University of Nebraska - Lincoln

DigitalCommons@University of Nebraska - Lincoln

\title{
Ureteral tunnel length versus ureteral orifice configuration in the determination of ureterovesical junction competence: A computer simulation model
}

\author{
Carlos A. Villanueva \\ University of Nebraska Medical Center, cvillanu@unmc.edu \\ J. Tong \\ University of Nebraska-Lincoln \\ Carl A. Nelson \\ University of Nebraska-Lincoln, cnelson5@unl.edu \\ Linxia $\mathrm{Gu}$ \\ University of Nebraska-Lincoln, gul@fit.edu
}

Follow this and additional works at: https://digitalcommons.unl.edu/mechengfacpub

Part of the Mechanics of Materials Commons, Nanoscience and Nanotechnology Commons, Other Engineering Science and Materials Commons, Other Mechanical Engineering Commons, Other Rehabilitation and Therapy Commons, Surgery Commons, and the Urology Commons

Villanueva, Carlos A.; Tong, J.; Nelson, Carl A.; and Gu, Linxia, "Ureteral tunnel length versus ureteral orifice configuration in the determination of ureterovesical junction competence: A computer simulation model" (2018). Mechanical \& Materials Engineering Faculty Publications. 303.

https://digitalcommons.unl.edu/mechengfacpub/303

This Article is brought to you for free and open access by the Mechanical \& Materials Engineering, Department of at DigitalCommons@University of Nebraska - Lincoln. It has been accepted for inclusion in Mechanical \& Materials Engineering Faculty Publications by an authorized administrator of DigitalCommons@University of Nebraska Lincoln. 


\title{
Ureteral tunnel length versus ureteral orifice configuration in the determination of ureterovesical junction competence: A computer simulation model
}

\author{
C. A. Villanueva, ${ }^{1}$ J. Tong, ${ }^{2}$ C. Nelson, ${ }^{2}$ and L. $\mathrm{Gu}^{2}$ \\ 1 University of Nebraska Medical Center/Children's Hospital and Medical \\ Center, Omaha, USA \\ 2 Department of Mechanical and Materials Engineering, University of \\ Nebraska-Lincoln, Lincoln, USA \\ Corresponding author - C. A. Villanueva, University of Nebraska Medical Center/ \\ Children's Hospital and Medical Center, 8200 Dodge Street, Omaha, NE 68114, USA; \\ tel 402-990-3634, email cvillanueva.uro@gmail.com
}

\begin{abstract}
Summary
Introduction

The long-held belief that a ureteral re-implant tunnel should be five times the diameter of the ureter, as proposed by Paquin in 1959, ignores the effect of the orifice on the occurrence of reflux. In 1969, Lyon proposed that the shape of the ureteral orifice (UO) is more important than the intravesical tunnel. However, both theories missed quantitative evidence from principles of physics. The goal of the current study was to test Lyon's theory through numerical models (i.e. to quantify the sensitivity of ureterovesical junction (UVJ) competence to intravesical tunnel length and to the $\mathrm{UO}$ ).

Materials and methods

The closure of a three-dimensional spatial configuration of ureter, constrained within a bladder, was simulated. Two common UO shapes (i.e. golf type vs $2-\mathrm{mm}$ volcano type (Summary Fig.)), and two different intravesical ureteral tunnel length/diameter ratios (3:1 and 5:1) were examined. The required closure pressures were then compared.
\end{abstract}


Results

The UO was a significant factor in determining closure pressure. Given the same intravesical ureteral tunnel length/ diameter ratio, the required closure pressure for the volcanic orifice was $78 \%$ less than that for the golf orifice. On the other hand, the intravesical ureteral tunnel length/diameter ratio had minimal effect on the required closure pressure. As the intravesical ureteral tunnel length/diameter ratio changed from $3: 1$ to $5: 1$, the required closure pressure was reduced by less than $7 \%$, regardless of the orifice shape.

\section{Conclusions}

The simulation results showed that UVJ competence was more sensitive to a 2-mm protrusion of the UO compared to an increase in the intravesical tunnel length from 3:1 to 5:1. This agrees with Lyon's theory, and at the same time challenges Paquin's 5:1 rule. Researchers could use this information to consider the UO configuration in further animal, human, computer or material models.

Keywords: Ureterovesical junction competence, Intravesical tunnel length, Ureteral orifice, Bladder, Finite element model
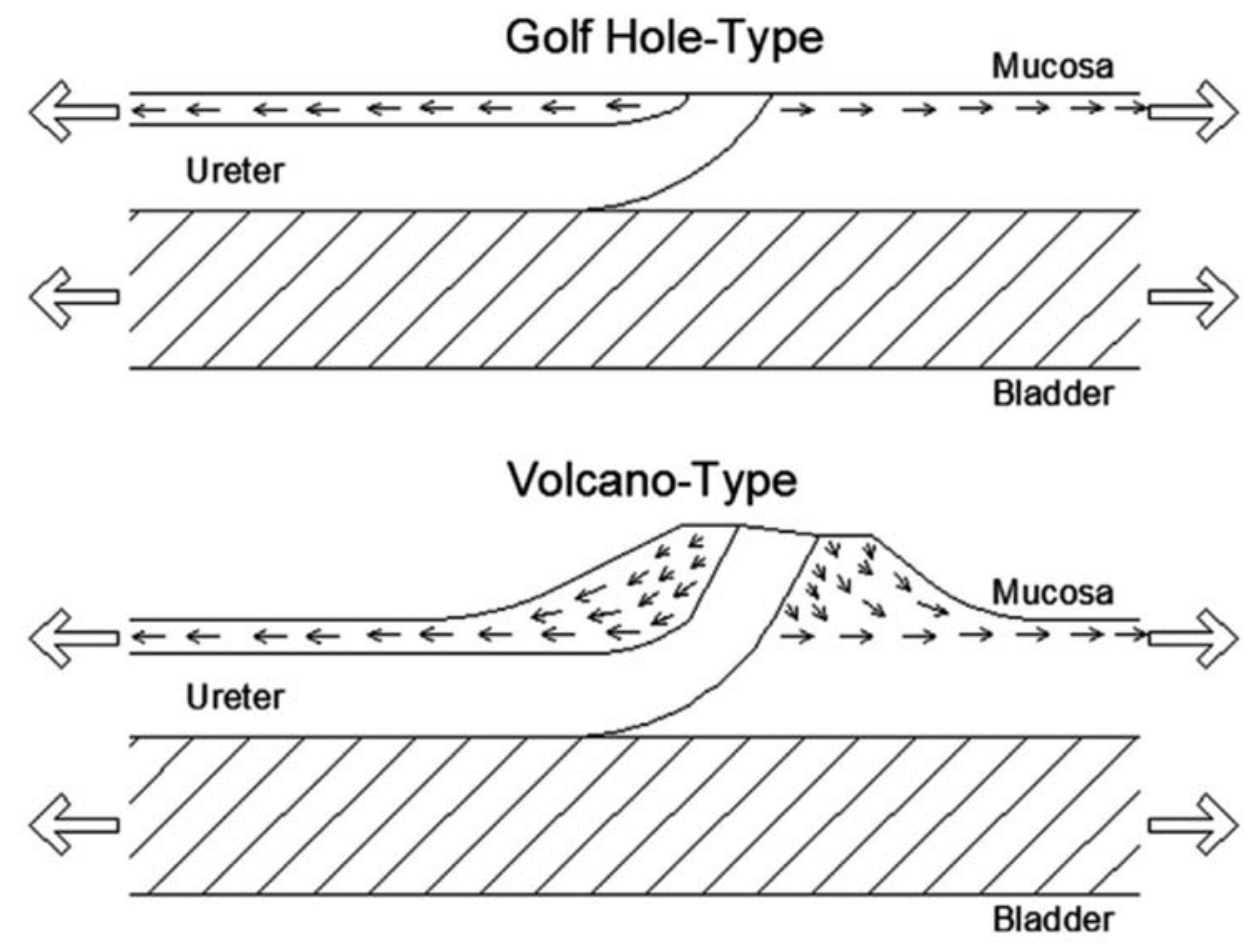

Summary Figure. Forces affecting a golf-type versus volcanic-type ureteral orifice. 


\section{Introduction}

In 1959, Paquin recommended a tunnel length five times the diameter of the ureter to prevent VUR; this was based on a comparison of postmortem specimens of patients with and without VUR [1]. In 1969, Lyon et al. [2] challenged Paquin's conclusions and proposed that the ureteral orifice (UO) was more important than the intravesical tunnel for ureterovesical junction (UVJ) competence.

Current surgical practice acknowledges Paquin's theory, since it is still recommended that a 5:1 tunnel be created when performing an open ureteral reimplantation. Lyon's theory might come into play when using bulking agents to affect the shape and configuration of the $U O$, but is not directly taken into consideration during surgical ureteral re-implants at the present time. Nevertheless, in his original 1959 manuscript Paquin described a technique to modify the spatial orientation of the UO by creating an intravesical cuff (Fig. 1, from Paquin's 1959 manuscript [1]). With regards to the cuff, Paquin stated that the cuff is '. thought to strengthen the $U O$ and make
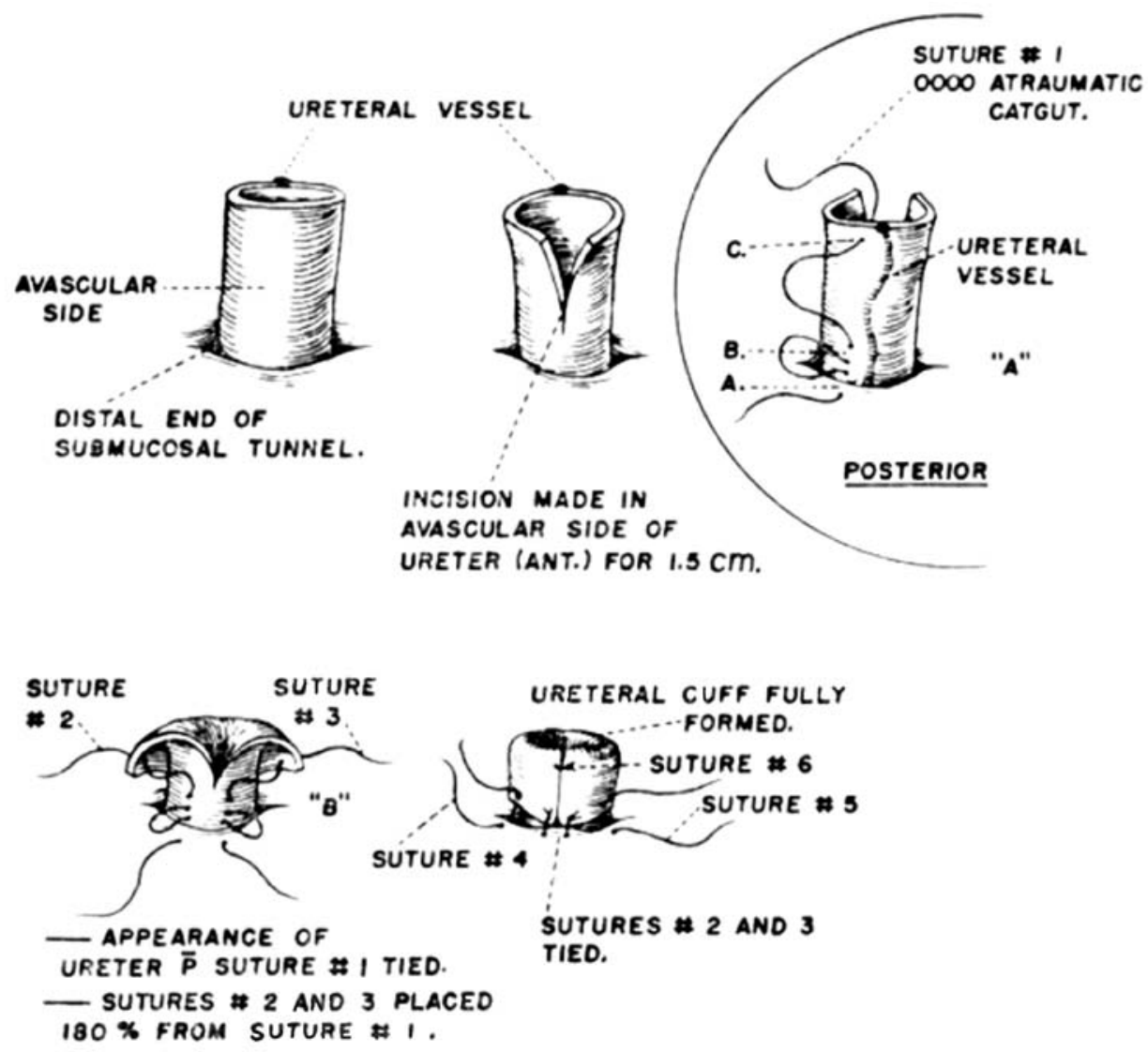

Figure 1. Paquin's 1959 paper Fig. 4. 
it more resistant to reflux'. Although Paquin's legacy was stripped down to the 5:1 rule, he clearly recognized the importance of the UO configuration.

No one has formally tested these two competing theories of UVJ competence. It is unknown if the two mechanisms of UVJ competence (tunnel length and $\cup O$ spatial orientation) are interdependent or if one is more critical. Since Paquin and Lyon, little research has looked at parameters regulating the prevention of VUR or leaking from Mitrofanoff-type conduits. Watson et al. studied the pressures inside Mitrofanoff conduits in relation to bladder pressures to determine functional profile length. They found a mean 3.4 $\mathrm{cm}$ in continent versus $1.8 \mathrm{~cm}$ incontinent patients [3], suggesting that longer intravesical tunnels are less likely to reflux.

Ureteral tailoring originated because of the 5:1 rule, given that there would not be any other way of creating a long enough tunnel on a dilated ureter and still follow the rule. A case control study of megaureter re-implants with and without ureteral tailoring found equivalent outcomes [4], raising concerns about the validity of the 5:1 rule. A previous computer model demonstrated that Paquin's ureteral tunnel length to diameter ratio of 5:1 did not fully explain the mechanisms of UVJ competence [5]. Furthermore, it found that the relationship was opposite of what Paquin originally proposed: shorter tunnels were needed for larger ureteral diameters. Additionally, the ureter material properties were found to have minimal impact on the pressure required to collapse the ureter. It was then speculated that the discrepancy between the model results and what happens clinically was related to the $U \mathrm{O}$, which was not modeled realistically in the previous computer models [5] (i.e. the UO that was modeled was independent of the bladder and not constrained by it). Thus, indirectly it was assumed that the UO was key in the mechanism of UVJ competence.

The purpose of the current study was to test the relationship of intravesical tunnel length and orifice shape with respect to VUR by measuring the pressure required to collapse the ureter for preventing backflow. An enhanced three-dimensional (3D) numerical model was developed, considering the interaction between the $U \mathrm{O}$ and the bladder wall. Parametric studies were then conducted to determine the sensitivity of UVJ competence to the spatial configuration of the intravesical tunnel as well as the UO.

\section{Materials and methods}

\section{Geometry}

A quarter of the bladder was constructed due to its symmetric shape. The 3D geometry of the ureter within this quarter of the bladder (Fig. 2a) was 
developed using commercial software SolidWorks 2012 (Dassault Systèmes Simulia Corp., Providence, RI, USA) [6]. This computer-aided design (CAD) software is often used to construct mechanical components, and is being increasingly used to model complex biomechanical components such as human organs and implants. Various commercial software could be used such as SolidWorks, Pro/Engineer, AutoCAD, or UniGraphics. SolidWorks was selected in this work due to its capacity to create complex solid and surface models. Four models were constructed in terms of different intravesical ureteral tunnel length/diameter ratios and orifice shapes. A bladder volume of $500 \mathrm{ml}$ and wall thickness of $1 \mathrm{~cm}$ were chosen [7]. The ureter diameter was assumed as $4 \mathrm{~mm}$. A tunnel length five times the ureter diameter (i.e. following Paquin's rule) was created along with the golf orifice (Fig. 2b). A shorter tunnel length (i.e. three times its diameter) (Fig. 2c) was also constructed for estimating the role of intravesical ureteral tunnel length/diameter ratio on UVJ competence. A volcanic orifice $2 \mathrm{~mm}$ high was created for both intravesical ureteral tunnel length/diameter ratios (Fig. $2 d$ and e) to conduct sensitivity analysis on the role of the orifice on UVJ competence.

\section{Mesh and boundary conditions}

The 3D models were then imported into ABAQUS 6.12 (Dassault Systèmes Simulia Corp., Providence, RI, USA) to perform nonlinear large deformation analysis [8]. Finite element methods provide an excellent means with which

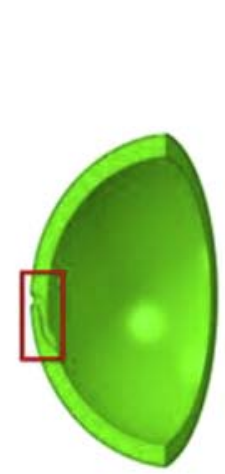

(a)

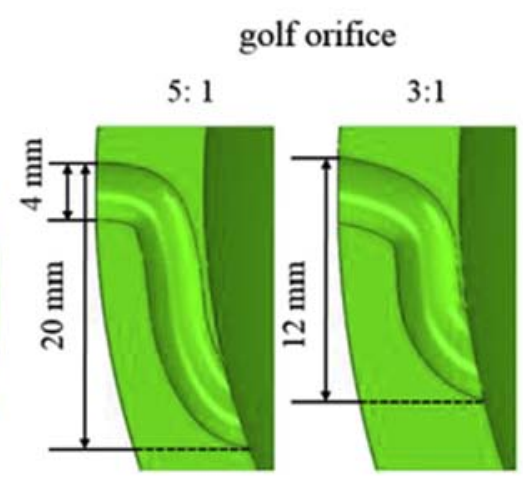

(b) (c)

volcanic orifice

$5: 1$

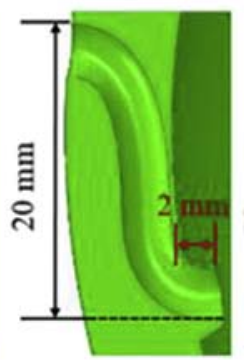

(d)

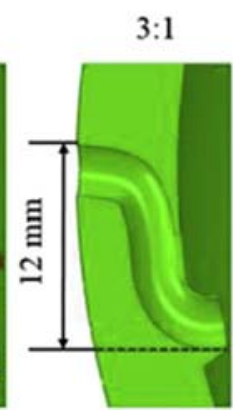

(e)

Figure 2. (a) 3D configuration of the UVJ model; (b) zoom-in view of ureter with 5:1 tunnel length with golf-type office; (c) 3:1 ureteral tunnel with a golf orifice; (d) 5:1 ureteral tunnel with a volcanic orifice; and (e) 3:1 ureteral tunnel with a volcanic orifice. 


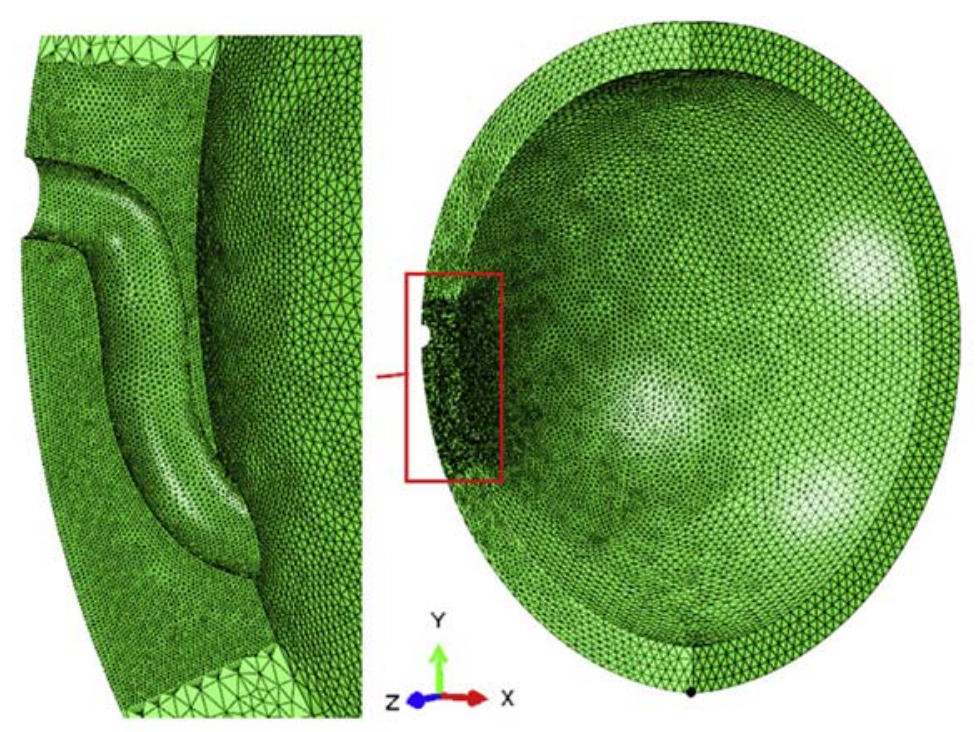

Figure 3. Finite element model of the UVJ within the bladder.

to investigate the physical rationales associated with UVJ. The simulation results could provide more datasets, specifically when experimental measurements are unavailable due to technical difficulties. For example, it has demonstrated its efficiency to quantify the strain and stress field on the aortic valve, leading to better understanding the mechanism of aortic valve closure $[9,10]$.

Symmetric boundary conditions were applied on cross sections of the bladder, and the bottom point of the bladder was fixed [11]. A linear ramping pressure was applied on the bladder inner surface. The material was meshed with hybrid four-node elements (C3D4H). Considering the complicated geometry near the ureter, the mesh density (i.e. the number of elements per unit volume) around the ureter was much higher than other regions (Fig. 3). The right image is the full view of the mesh with the zoom-in view around the ureter. A mesh convergence study was conducted to ensure that results were not affected by mesh density. A total of 169,059 elements were chosen for the model (Fig. 4).

A hyperelastic constitutive model was used for the tissue properties. The Yeoh constitutive law has been used in numerous studies of natural polymer materials and rubberlike materials (e.g. carotid arteries) [12]. The constitutive equation in terms of strain energy density function $\mathrm{W}$ is the following:

$$
W=C_{10}\left(\bar{I}_{1}-3\right)+C_{20}\left(\bar{I}_{1}-3\right)^{2}+C_{30}\left(\bar{I}_{1}-3\right)^{3}
$$

where $C_{i 0}$ are material parameters and $I_{1}$ is the first invariant of the CauchyGreen strain tensor as

$$
\bar{l}_{1}=\bar{\lambda}_{1}^{2}+\bar{\lambda}_{2}^{2}+\bar{\lambda}_{3}^{2}, \quad \bar{\lambda}_{i}^{2}=J^{-1 / 3} \lambda_{i}^{2}
$$




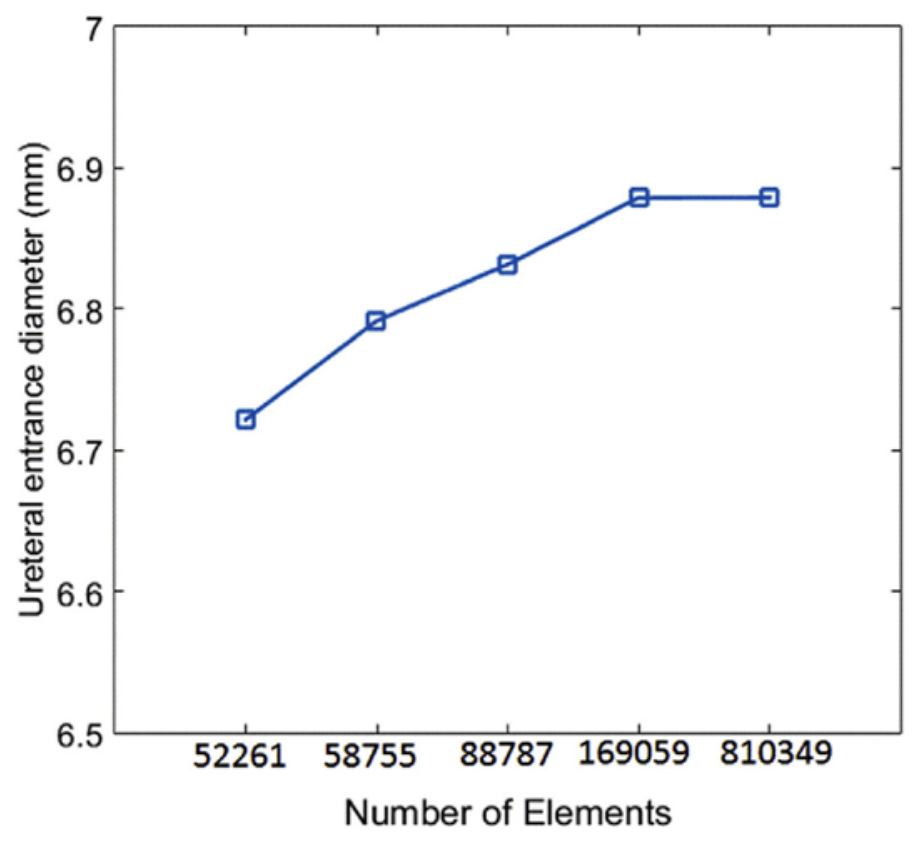

Figure 4. Mesh convergence study.

where $\lambda_{i}$ are the principal strains and $J$ is the total volume ratio. The experimental data from Dahms's previous work [11] was used to fit the material constants such as $C_{10}=3.04 \times 10^{-3} \mathrm{MPa}, C_{20}=8.03 \times 10^{-2} \mathrm{MPa}$, and $C_{30}=$ $-2.03 \times 10^{-2} \mathrm{MPa}$.

\section{Results}

The bladder volume changes and the corresponding ureter pre-closure and post-closure are depicted in Fig. 5. The left image is the full view of the model with two zoom-in views. Fig. 5a and b represents the ureter morphology in the shaded and green part of the left image, respectively. The closure pressure was quantified when the inner diameter was reduced to $70 \%$ of its original value, which is summarized in Table 1 for the different tunnel and orifice configurations. Closure pressure for the $5: 1$ tunnel was $22.63 \mathrm{cmH}_{2} \mathrm{O}$ for the golf orifice versus $4.85 \mathrm{cmH}_{2} \mathrm{O}$ for the volcano orifice, and for the 3:1 tunnel the values were $24.37 \mathrm{cmH}_{2} \mathrm{O}$ and $5.25 \mathrm{cmH}_{2} \mathrm{O}$, respectively. As can be seen in Table 1, increasing the ureteral tunnel length marginally influenced the closure pressure: given the same orifice configuration, changing the tunnel length from 3:1 to 5:1 reduced closing pressures by about $7 \%$. On the other hand, keeping the same ureteral tunnel length, changing the configuration of the UO from golf type to volcanic greatly reduced the closing pressures by about $78 \%$. 

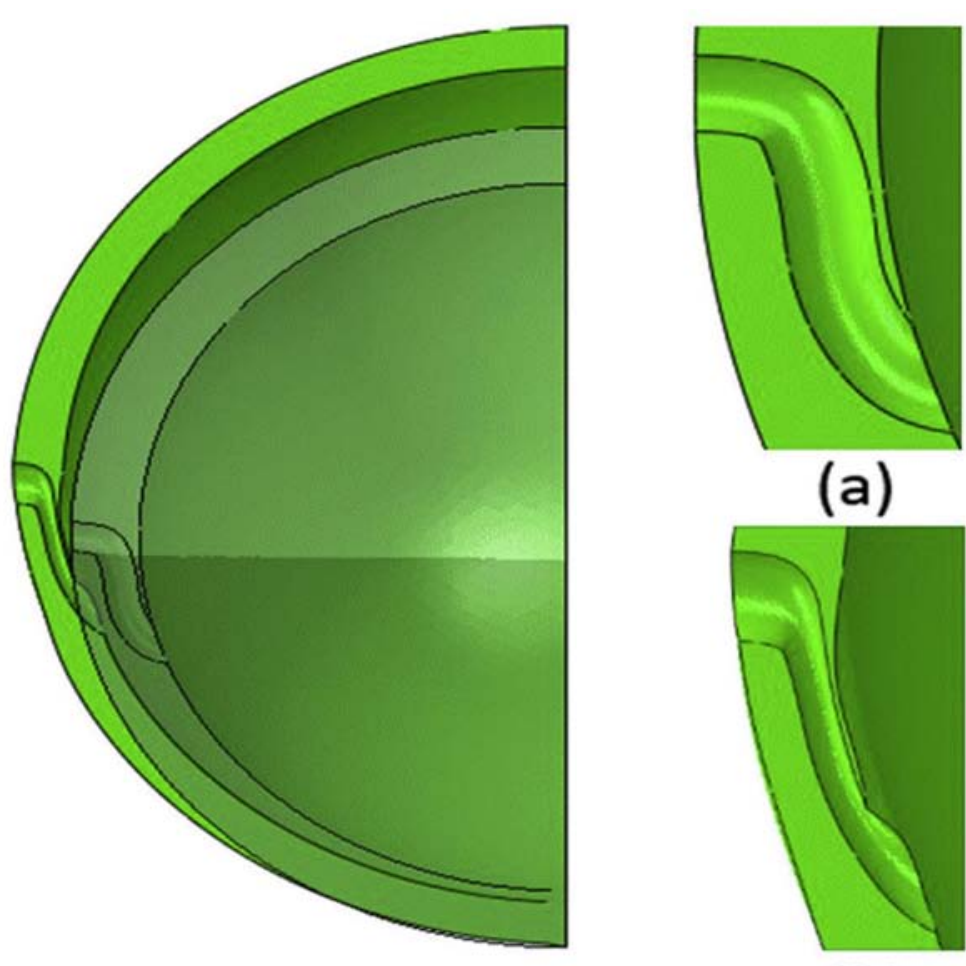

(a)

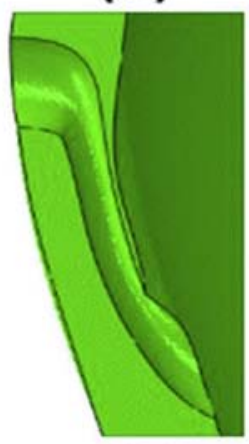

(b)

Figure 5. The bladder pressure induced ureteral closure with its zoom-in view at zero pressure (a) and closure pressure (b), respectively.

Table 1. Closure pressures in relation to ureteral tunnel length, diameter and orifice shape.

\begin{tabular}{lcc}
$\begin{array}{l}\text { Ureter tunnel length } \\
\text { (tunnel length/ } \\
\text { diameter ratio) }\end{array}$ & $\begin{array}{c}\text { Ureter closing pressure } \\
\left(\mathrm{cmH}_{2} \mathrm{O}\right)\end{array}$ \\
\hline $20 \mathrm{~mm} \mathrm{(5:1)}$ & $\begin{array}{c}\text { Golf } \\
\text { orifice shape }\end{array}$ & $\begin{array}{c}\text { Volcano } \\
\text { orifice shape }\end{array}$ \\
$12 \mathrm{~mm} \mathrm{(3:1)}$ & 22.63 & 4.85 \\
\hline
\end{tabular}

\section{Discussion}

The current study confirms the speculations generated from previous models [5] that the UO configuration plays a significant role in UVJ competence. Small changes in the configuration of the UO $(2 \mathrm{~mm}$ volcanic configuration) resulted in significant decreases in closing pressure, whereas increasing the tunnel length from 3:1 to 5:1 marginally affected the closing pressure. This could be explained by the intrinsic constraints of the bladder wall 

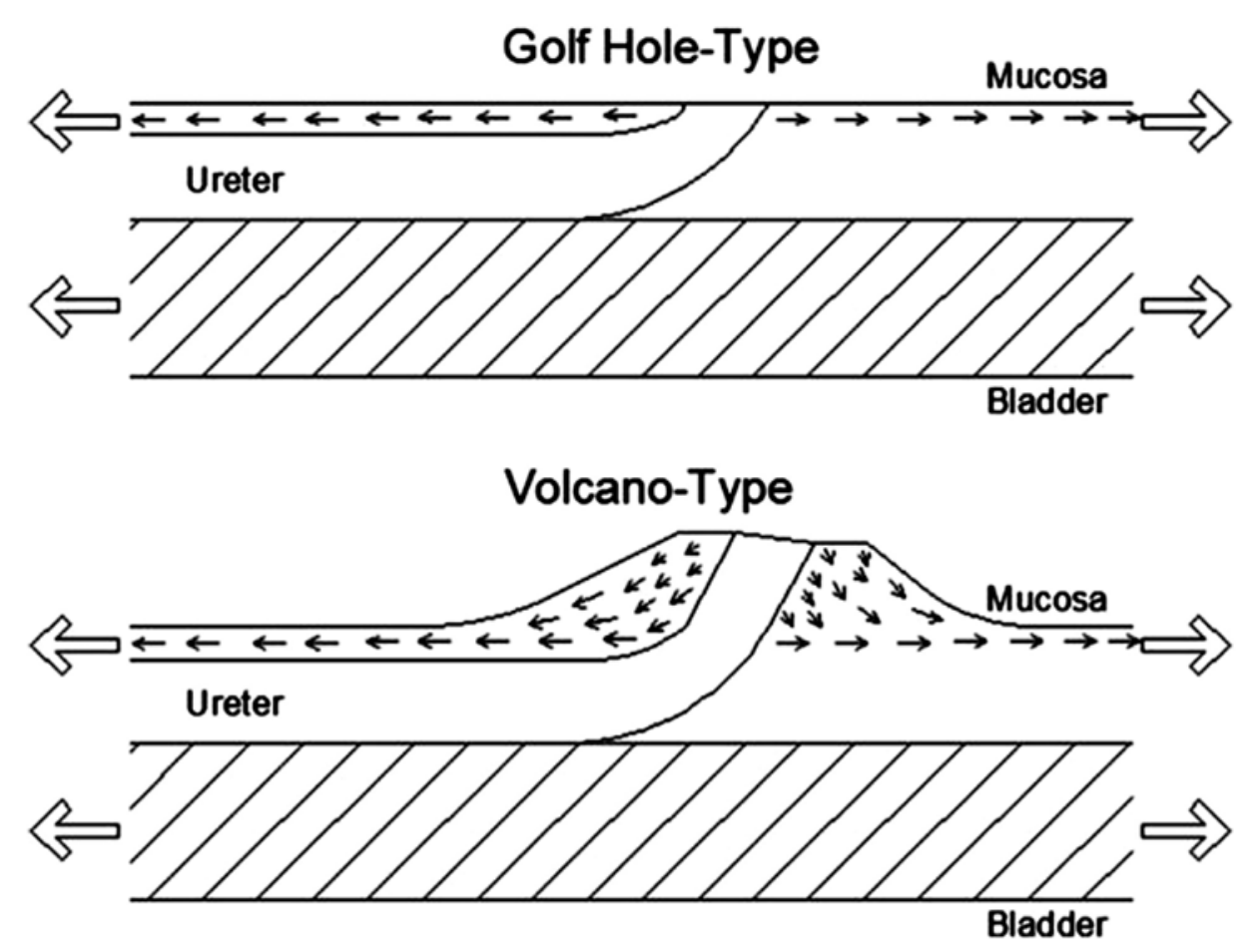

Figure 6. Forces affecting a golf-type versus volcanic-type ureteral orifice.

on the UO. The volcanic UO was easier to be closed due to its geometric configuration, which was less constrained by the bladder wall compared to the golf-type UO.

The physics of the 5:1 rule never quite made mathematical sense, as tube diameter affects flow of fluid through an exponential relation as opposed to a linear relation, as Paquin's rule described. The physics explanation of the effect of the volcanic orifice is likely due to the isolating effect from the stretching forces of the bladder: in other words, bladder stretch by filling opens a golf-type UO easier than a volcanic orifice (Fig. 6).

The aim of the current study was not to try to improve existing ureteral reimplantation techniques but to get a better understanding of how and why the current techniques work. Unfortunately, there is no equation that predicts the function of the UVJ and which incorporates all the variables: ureteral diameter, tunnel length, ureteral orifice configuration, ureteral thickness, etc. The current findings should inform investigators embarking upon the subject matter about the need to consider the spatial configuration of the ureteral orifice in future models.

Although the modification of the intravesical ureteral orifice is not part of current re-implantation techniques, ironically Paquin described it in his 1959 manuscript (Fig. 1, from Paquin's 1959 manuscript [1]). More recently, 
Liu et al. [13] published a modified technique to re-implant megaureters, where the only part modified was the UO: the ureter was made to protrude inside the bladder without affecting the intravesical tunnel, with a postoperative VUR rate of $1 / 13$. This last study supports the current finding, since reflux was avoided by just modifying the ureteral orifice configuration.

It is acknowledged that the current models have serious limitations, since they model collapse as a surrogate for actual urine backflow. In the natural state it would be assumed that the ureter is collapsed, and as the bladder is filled the intravesical pressure increases, and depending on the UO configuration and tunnel length, ureteral opening and then reflux might then occur. Also, in the current models the width of the ureter cannot be larger than the width of the bladder, since the ureter was not modeled to travel in between the bladder mucosa and the muscle, but instead travels inside the muscle. The last limitation of the current model is that the ureter never fully collapses. Despite these limitations it is believed that this current model makes a compelling argument for the role that the $U O$ configuration plays in UVJ competence.

\section{Conclusions}

This study suggests that the UO configuration plays an important role with regards to UVJ competence. Researchers could use this information to consider the UO configuration in further animal, human, computer or material models.

Conflicts of interest - The authors have no conflicts of interest.

Funding - The study was funded by the Department of Surgery, section of Urology at the University of Nebraska Medical Center.

\section{References}

[1] Paquin Jr AJ. Ureterovesical anastomosis: the description and evaluation of a technique. J Urol 1959;82:573-83.

[2] Lyon RP, Marshall S, Tanagho EA. The ureteral orifice: its configuration and competency. J Urol 1969;102(4):504-9.

[3] Watson HS, Bauer SB, Peters CA, Mandell J, Colodny AH, Atala A, et al. Comparative urodynamics of appendiceal and ureteral Mitrofanoff conduits in children. J Urol 1995;154(2 Pt 2):878-82. 
[4] Ben-Meir D, Livne PM, Feigin E, Djerassi R, Efrat R. Meatotomy using local anesthesia and sedation or general anesthesia with or without penile block in children: a prospective randomized study. J Urol 2011;185(2):654-7.

[5] Villanueva CA, Nelson CA, Stolle C. Intravesical tunnel length to ureteral diameter ratio insufficiently explains ureterovesical junction competence: a parametric simulation study. J Pediatr Urol 2015;11(3):144.e1-5.

[6] Valentino JDN. SolidWorks for technology and engineering. South Norwalk, Connecticut: Industrial Press, Inc.; 2010.

[7] Kaefer M, Zurakowski D, Bauer SB, Retik AB, Peters CA, Atala A, et al. Estimating normal bladder capacity in children. J Urol 1997;158(6):2261-4.

[8] Kristiansen NK, Ringgaard S, Nygaard H, Djurhuus JC. Effect of bladder volume, gender and body position on the shape and position of the urinary bladder. Scand J Urol Nephrol 2004; 38(6):462-8.

[9] Haj-Ali R, Dasi LP, Kim HS, Choi J, Leo HW, Yoganathan AP. Structural simulations of prosthetic tri-leaflet aortic heart valves. J Biomech 2008;41(7):1510-9.

[10] Jermihov PN, Jia L, Sacks MS, Gorman RC, Gorman 3rd JH, Chandran KB. Effect of geometry on the leaflet stresses in simulated models of congenital bicuspid aortic valves. Cardiovasc Eng Technol 2011;2(1):48-56.

[11] Dahms SE, Piechota HJ, Dahiya R, Lue TF, Tanagho EA. Composition and biomechanical properties of the bladder acellular matrix graft: comparative analysis in rat, pig and human. Br J Urol 1998;82(3):411-9.

[12] Lawlor MG, O'Donnell MR, O'Connell BM, Walsh MT. Experimental determination of circumferential properties of fresh carotid artery plaques. $J$ Biomech 2011;44(9):1709-15.

[13] Liu W, Du G, Guo F, Ma R, Wu R. Modified ureteral orthotopic reimplantation method for managing infant primary obstructive megaureter: A preliminary study. Int Urol Nephrol 2016; 48(12):1937-41. 